\title{
Effects of interpolated activity on short-term kinesthetic memory
}

\author{
GERALD W. BARNES and JERRY R. HENDERSON \\ University of Arkansas at Little Rock, Little Rock, Arkansas 72204
}

\begin{abstract}
Effects of motor and of verbal interpolated activities on short-term retention of grip tensions were studied in relation to effects of unoccupied retention intervals. Basic measure was absolute error made in attempts to reproduce an initial grip tension after retention intervals of $0,5,10$, or 20 sec. Both verbal (counting backward by threes) and motor (a kinesthetic analogue to counting backwards) tasks were shown to increase absolute error, as linear functions of retention interval, relative to a control. Short-term kinesthetic decrement functions were similar to those reported for auditory and for visual stimuli, suggesting some common process(es) underlying verbal, visual, and kinesthetic short-term memory.
\end{abstract}

By and large, studies of short-term kinesthetic memory have involved retention of lever-positioning responses (Posner, 1967; Stelmach \& Wilson, 1970), with interpolated "distractor" activities typically requiring either verbal (e.g., summing angles) or additional lever-positioning responses. Short-term retention of lever-positioning seems to be a loss function (Adams \& Dijkstra, 1966), but Posner (1967) reported that effects of verbal distractors were no different from decay associated with unfilled retention intervals. There are findings which conflict with Posner's (1967) in some details (Pepper \& Herman, 1970), and one conclusion has been essentially that motor short-term retention is an inverse function of similarity between original and interpolated movements (Craft \& Henrichs, 1971), at least for short movements (Stelmach \& Wilson, 1970). Perhaps some kinesthetic short-term retention follows a course similar to verbal retention (Peterson \& Peterson, 1959) with some kinds of interpolated activities, though other conclusions are the rule (Posner, 1967).

Unfortunately, conditions under which systematic, progressive kinesthetic decay is demonstrable are rather obscure, and the range of studied interpolated tasks is restricted. At this point, it would seem that kinesthetic retention data generated by a method specifically comparable to the classic Peterson and Peterson (1959) procedure would be helpful. The desired method must, at a minimum, introduce interpolated behaviors of the same general class as the to-be-retained input, but also be of categorically different content. We think the method described below fulfills those requirements and may aid in clarifying basic retention mechanisms.

\section{METHOD}

Subjects

Subjects were 13 male and 7 female University of Arkansas at

This paper is sponsored by O. D. Murphee, who accepts full editorial responsibility for its contents.
Little Rock undergraduates participating for course credit.

\section{Apparatus}

Grip strengths were measured by a C. H. Stoelting Co. Model $19117-\mathrm{P}, 0-100-\mathrm{kg}$ hand dynamometer, fixed vertically behind a flat-black panel out of a subject's view. A $33 \times 46 \mathrm{~cm}$, flat-black, $1.6-\mathrm{cm}$-thick particle board, with six $4.8-\mathrm{mm}$ machine screws protruding $3.2 \mathrm{~cm}$ above the board's surface, defined the motor interpolated task detailed below. A nut was threaded onto each screw, and screws were expanded to prevent removal of nuts. Screws were arranged $12.7 \mathrm{~cm}$ apart in two rows parallel to, and inset $10 \mathrm{~cm}$ from, the shorter dimension of the board. Retention intervals were timed by a Grason-Stadler Model 1180 electronic timer.

\section{Procedure}

Before the study proper began, a subject's "maximum grip strength" was determined as the average of two readings obtained under instructions to: "Point this straight at the floor, at your side and at arm's length, and squeeze it as hard as you can." Criterion (i.e., to-be-retained) pressures of $15 \%, 30 \%$, and $45 \%$ of maximum grip were then calculated and entered in a running sheet for that subject. Running sheets specified an order of the retention intervals $0,5,10$, and $20 \mathrm{sec}$, randomized in blocks of four trials each with the restriction that no two successive intervals be identical. A random order of criterion pressures was also specified, with the restriction that each pressure occur equally at each nonzero retention interval. An order of "counting" and "motor" interpolated tasks was also specified within four-trial blocks, randomized with the constraints that each task type occur twice and be equally represented at every nonzero retention interval and at every criterion pressure over the total of 32 trials.

Each trial began with positioning a subject's preferred hand in the dynamometer grip saddle. On verbal cue, the subject slowly increased grip tension until the command, "Stop," spoken at criterion tension. Simultaneously with "Stop," a switch closure began timing a retention interval. Prior to a trial, experimental group subjects were told which of two interpolated tasks they were to do on that trial. On "counting" trials, the subject removed his hand from the dynamometer at "Stop" and a three-digit random number was immediately read; the subject repeated that number and began counting backwards by threes until a bell sounded, signaling an attempt to reproduce criterion pressure. "Motor" trials required the same basic procedure as did "counting" trials, except that subjects were told to use both hands simultaneously to turn nuts (clockwise) until a nut had been threaded against the board, then to move on to the next set of screws, working from front to rear of the board until criterion recall signal. No other external 


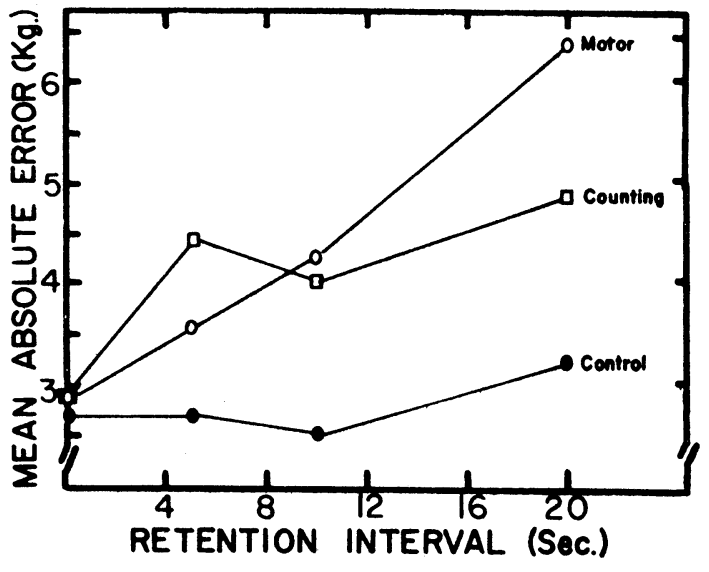

Figure 1. Mean absolute grip reproduction error over retention intervals.

timing cues were provided-instructions were simply to perform interpolated tasks as rapidly as possible.

Retention intervals for control subjects were unfilled, with subjects sitting quietly until signaled to reproduce criterion pressure for that trial. All subjects were given two practice trials, questions were answered by paraphrasing the standard instructions, and the experiment proper began.

\section{RESULTS}

Trend analyses were done at each retention interval, for each group and each interpolated task, over absolute grip reproduction errors as a function of criterion tension. No trends emerged at the .05 level of confidence, and reproduction errors were thus pooled across criterion tensions.

Mean absolute differences between criterion and recall tensions are shown in Figure 1, for both groups and both interpolated tasks, as a function of retention interval. We assessed differences between counting and motor data by subtracting, for each subject, mean motor error from mean counting error at each nonzero retention interval. The "counting-motor" values were then trend analyzed over retention intervals, yielding a significant linear component of trend $[F(1,18)=4.62, p<.05]$. We conclude that effects of the two distractors upon absolute error in tension recall were different, with the motor task producing recall errors increasing over retention intervals at the faster rate. Motor and counting data were then trend analyzed separately, revealing significant trend with only a linear component for both tasks: $F(1,27)=19.16, p<.005$, for motor; $\mathrm{F}(1,27)=6.72, \mathrm{p}<.025$, for counting. Control group analysis unearthed no significant trends (all Fs $<1.00$ ), and we further conclude that genuine short-term memory loss has been shown as a function of our two distractors, relative to no-decrement with unfilled intervals.

\section{DISCUSSION}

The motor task described above was devised to require using many of the local upper extremity muscle groups involved in gripping but with different detailed response topography, and thus seemed to offer a kinesthetic analogue to major features of the original Peterson and Peterson (1959) paradigm for demonstrating verbal short-term forgetting. Both upper extremities were required in the motor task to reduce the likelihood of contralateral muscular retention via bilateral transfer. We here report significant short-term grip retention loss as a linear function of retention interval for the motor distractor, and in some sense we have apparently duplicated one aspect of classic verbal short-term memory data. To be sure, usual functions reported for recall of verbal materials are rapidly falling, decelerating functions asymptotic at some near-zero value, while the kinesthetic decremental function we found appears to be linear. Comparability of dependent variables obviously cannot be defended, however, in evaluating equivalence of verbal decay functions and the kinesthetic function we report. It seems prudent to infer only that our motor task did in fact generate increasing short-term kinesthetic recall loss over retention intervals, as do distractors equivalent to our motor task in studies of verbal short-term forgetting.

Of the two distractors here used, the motor one produced the more short-term loss and one may infer that some variables relating to local muscle states are important in retaining the sort of kinesthetic input we examined. Yet, statistically reliable decrement was shown with counting backward by threes as a distractor, so that local muscle tensions apparently do not exhaust the range of relevant factors. Other data from our laboratory (Barnes, Nutt, \& Souheaver, Note 1) dealing with short-term recognition of random dot patterns show increasing retention decrement using distractors requiring random eye movements, or generalized muscular exercise, or counting backward by threes; in fact, those data in part suggested the present study, and we find the similarity between our kinesthetic findings and our visual results to be striking. A straightforward conclusion could be that short-term memory for a specific input has elements which include (a) muscle tensions associated directly with the input areas and (b) the verbalizing apparatus. Such a conclusion is certainly not novel. Some early introspective reports concerning imagery were of frankly kinesthetic content (see reviews in Woodworth, 1937). Jacobson (1932) reported activity in vocal, as well as in local, musculature with essentially any "imagining" activity by his relaxed subjects. Theories relating thought and retention to subvocal, or to more generally motor, activities are well known, if now in some disrepute.

Our findings are clearly in line with behavioral thinking, i.e., that short-term memory involves translation of an input into some unique response pattern. Then, accuracy of recall would depend upon the extent to which that response pattern can be maintained during a retention interval and/or the extent to which conflicting responses are learned during a retention interval. Whatever the ultimate theoretical outcome, our data at least indicate commonalities in short-term forgetting for verbal, for visual, and for kinesthetic stimuli. We thus suggest that stimuli are coded for short-term storage via the same basic conditioning process for all in put modalities. It may not now be implausible to suggest further that the "central short-term register" (Atkinson \& Shiffrin, 1968) may relate to verbal coding per se which has very high probability for vocal organisms for any input, and that the remaining musculature offers a storage mechanism which, under favorable circumstances, might considerably expand short-term retention capability.

\section{REFERENCE NOTE}

1. Barnes, G. W., Nutt, L., \& Souheaver, G. Short-term visual memory: Behavioral? Manuscript submitted for publication, 1975. 


\section{REFERENCES}

Adams, J. A.. \& Dijkstra, S. Short-term memory for motor responses. Journal of Experimental Psychology, 1966, 71. 314-318.

Atkinson, R. C., \& Shiffrin, R. M. Human memory: A proposed system and its control processes. In K. W. Spence, \& J. T. Spence (Eds.). The psychology of learning and motivation (Vol. 2). New York: Academic Press, 1968.

Craft, J. L., \& Henrichs, J. V. Short-term retention of simple motor response: Similarity of prior and succeeding response. Journal of Experimental Psychology, 1971, 87, 297-302.

JACOBson, E. Electrophysiology of mental activity. American Journal of Psychology. 1932, 44, 677-694.

Pepper, R. L., \& Herman, L. M. Decay and interference effects in the short-term retention of a discrete motor act. Journal of Experimental Psychology Monograph, 1970, 83. (2. Pt. 2).
Peterson. L. R.. \& Peterson, M. J. Short-term retention of individuai verbal items. Journal of Experimental Psychology, 1959. 58. 193-198.

Posner. M. I. Characteristics of visual and kinesthetic memory codes. Journal of Experimental Psychology, 1967, 75, 103-107.

Stelmach, G. E., \& Wilson, M. Kinesthetic retention, movement extent, and information processing. Journal of Experimental Psychology, 1970, 85, 425-430.

Woodworth, R. S. Experimental psychology, New York: Holt, 1937.

(Received for publication June 19, 1975.) 